\title{
An Analysis of Affecting the Teaching of Table Tennis Optional Course by the Factor of College Students' Physical Fitness Test Data
}

\author{
Shu-Ping XU ${ }^{1, a^{*}}$, Li-Xin LIANG ${ }^{2, b}$, Jin-Suo REN ${ }^{3, c}$
}

1 Department of Physical Education, North China Electric Power University, Beijing, China

2 School of Continuing Education, North China Electric Power University, Beijing, China

3 Department of Physical Education, North China Electric Power University, Beijing, China

a ${ }^{*}$ xuping7877@sina.com, b1982491624@qq.com, c1697780921@qq.com, ${ }^{\text {d }}$

Keywords: Table tennis optional course, teaching, physical test, data factor, analysis and research.

\begin{abstract}
In this paper, the influence of the various physical test data of college students in the learning process of table tennis is investigated, and the freshman and sophomore students' physical fitness test results of all the table tennis optional course classes in North China Electric Power University are analyzed as the data resource. The data analysis adopts the software SPSS 20.0 as the main tool, which is easy to study and utilize, and the relevant component analysis is conducted. Finally, significance of the various items of the physical test to the improvement of table tennis skills and the tactical level is clarified, and the balance of the exercise intensity and speed is discussed.
\end{abstract}

\section{Introduction}

With the growing universality and popularity of table tennis in colleges, both the professional table tennis teams of all levels and the ordinary table tennis students put forward higher requirements of themselves. However, limited by the given teaching hours and the uneven degrees of mastery of the students, the college education teams are promoted to take coordinate measures. In the teaching process of table tennis in North China Electric Power University, the concept of dan ranking system are introduced, which is used in Go, Taekwondo and some other competitive projects. In one or more natural classes, students are organized to participate in random games, and the winners obtain corresponding points, thus determining the dan ranking according to the number of points.

In the teaching practice of more than one year, it is found that the gaps of dan ranking points among the students in each class are considerably obvious. The reasons for the huge gaps given the same teaching and training environment are closely related to the levels of physical quality of the students.

\section{Research Objects and Methods}

\section{Research Objects}

The relationship between the physical conditions and the dan ranking points of the students in the table tennis optional course classes in North China Electric Power University is taken as the research object.

\section{Research Methods}

\section{Method of Documentary Information}

Various CNKI sports journals, monographs and other related literature are investigated, including Sports Science, China Sports Science and Technology, Journal of Beijing Sport University, Journal of Wuhan Institute of Physical Education, Journal of Hebei Institute of Physical Education and so on. These documents provide a theoretical basis for this paper. 


\section{Method of General Questionnaire}

General questionnaires of 500 copies are distributed to the students, 480 of which are collected, and the effective recovery rate is $96 \%$.

\section{Method of Measurement}

Based on the requirements of National Student Physical Health Standard, the students in the table tennis optional course classes of the 2014 class in North China Electric Power University are tested. The test indicators are height, weight, vital capacity, seat flexion, pull-up, standing long jump, 50-meter race, and 1000-meter race.

\section{Method of Measurement}

The SPSS 20.0 software is adopted in the factor analysis for the data obtained by the tests.

\section{Results and Analysis}

\section{Selection of Test Items}

According to the research needs, based on the extensive expert consultation and the theory of sports training and table tennis physical fitness training, a questionnaire survey to 15 table tennis experts is conducted. The questionnaire coordinates with the design principles and methods of sports evaluation questionnaires, and reliability tests are conducted to Two Rounds of Expert Questionnaire Survey of College Students Table Tennis Physical Fitness. According to the college table tennis student physical quality test indicators project identified by the two rounds of expert questionnaire, 93 of the surveyed students take the special physical indicators tests. In order to ensure the reliability and credibility of the tests, the questionnaire survey and consultation of the 20 experts are carried out. Therefore, 7 tests indicators with recognition rate of above $90 \%$ are selected from 15 indicators in the initial selection, namely: 1000-meters race, 800-meters race, vital capacity, seat flexion, pull-up, standing long jump, 50-meters race BMI. The indicators above are set as the final test indicators.

\section{Test Results}

The original data of the 8 special physical indicators of the 93 students are input into the SPSS 20.0 software. Statistical analyses are carried out, and the average values of the test indicators are obtained (Table 1).

Table 1. Indicators of physical quality test results

\begin{tabular}{|c|l|l|l|l|l|}
\hline & $\mathrm{N}$ & $\begin{array}{l}\text { Minimu } \\
\text { m value }\end{array}$ & $\begin{array}{c}\text { Maxim } \\
\text { um } \\
\text { value }\end{array}$ & $\begin{array}{l}\text { Averag } \\
\text { e value }\end{array}$ & $\begin{array}{l}\text { Sstandard } \\
\text { deviation }\end{array}$ \\
\hline BMI & 93 & 16.2519 & 30.7855 & $\begin{array}{l}21.3459 \\
05\end{array}$ & 2.9843527 \\
\hline Vital capacity & 93 & 1675 & 5615 & 3803.10 & 720.875 \\
\hline $\begin{array}{c}\text { 50-meters race } \\
\text { B-men or } 800\end{array}$ & 93 & 6.6000 & 9.2000 & $\begin{array}{l}7.88387 \\
1\end{array}$ & .5180000 \\
\hline $\begin{array}{c}1000 \\
\text { meters race }\end{array}$ & 93 & 1.9000 & 36.2000 & $\begin{array}{l}15.5387 \\
10\end{array}$ & 6.1912637 \\
\hline $\begin{array}{c}\text { Seat flexion } \\
\text { Standing long } \\
\text { jump }\end{array}$ & 93 & 173 & 280 & 216.41 & 19.154 \\
\hline $\begin{array}{c}\text { Pull-up or one } \\
\text { minute sit-up }\end{array}$ & 93 & 0 & 15 & 3.87 & 3.968 \\
\hline
\end{tabular}


Table 1 reflects the average level of the physical quality test items of 80 students in the table tennis classes, but fails to reflect the relationships among the indicators. Due to the limited sample capacity, in order to clarify the huge difference among the students in the dan ranking points, we need to extract information from the limited data. The relationships of the special physical quality test indicators of table tennis students, as well as their interaction, comprise of the physical quality system of the table tennis students. With the factor analysis, we can clarify the structure and function of the physical quality system of the students and the relationships of the elements.

The data amount of the sample selection in this research is obtained as big as possible given the limited amount of students, and satisfies the statistical characteristic in the SPSS social statistic software that the bigger the sample amount is, the more accurate the analysis results are. The KMO of the indicator analysis in this paper and the spherical Bartle II test results show that $\mathrm{K}=0.689$, indicating that the sample factor analysis is satisfactory. The Sig value of the Bartle test is 0.000, $\mathrm{p}<0.01$, indicating that the sample data satisfy the multiple normal distribution, and can be further analyzed.

Table 2. Total variance analysis of factor analysis

\begin{tabular}{|c|c|c|c|c|c|c|c|c|}
\hline \multirow[t]{2}{*}{$\begin{array}{l}\text { Compone } \\
\text { nts }\end{array}$} & \multicolumn{3}{|c|}{ Initial eigenvalue } & \multicolumn{3}{|c|}{$\begin{array}{l}\text { Extraction quadratic } \\
\text { loading }\end{array}$} & \multicolumn{2}{|c|}{$\begin{array}{l}\text { Rotation } \\
\text { quadratic } \\
\text { loading }\end{array}$} \\
\hline & $\begin{array}{c}\text { Tot } \\
\text { al }\end{array}$ & $\begin{array}{c}\text { Percenta } \\
\text { ge } \\
\text { of } \\
\text { variance }\end{array}$ & $\begin{array}{c}\text { Accumulat } \\
\text { ive } \\
{[\%]}\end{array}$ & $\begin{array}{c}\text { Tot } \\
\text { al }\end{array}$ & $\begin{array}{c}\text { Percenta } \\
\text { ge } \\
\text { of } \\
\text { variance }\end{array}$ & $\begin{array}{c}\text { Accumulat } \\
\text { ive } \\
{[\%]}\end{array}$ & $\begin{array}{c}\text { Tot } \\
\text { al }\end{array}$ & $\begin{array}{l}\text { Percenta } \\
\text { ge } \\
\text { of } \\
\text { variance }\end{array}$ \\
\hline 1 & $\begin{array}{l}2.07 \\
8\end{array}$ & 29.683 & 29.683 & $\begin{array}{l}2.07 \\
8\end{array}$ & 29.683 & 29.683 & $\begin{array}{l}2.01 \\
6\end{array}$ & 28.798 \\
\hline 2 & $\begin{array}{l}1.47 \\
9\end{array}$ & 21.127 & 50.810 & $\begin{array}{l}1.47 \\
9\end{array}$ & 21.127 & 50.810 & $\begin{array}{l}1.43 \\
0\end{array}$ & 20.434 \\
\hline 3 & $\begin{array}{l}1.20 \\
5\end{array}$ & 17.217 & 68.027 & $\begin{array}{l}1.20 \\
5\end{array}$ & 17.217 & 68.027 & $\begin{array}{l}1.31 \\
6\end{array}$ & 18.796 \\
\hline 4 & .704 & 10.061 & 78.088 & & & & & \\
\hline 5 & .582 & 8.311 & 86.399 & & & & & \\
\hline 6 & .511 & 7.300 & 93.699 & & & & & \\
\hline 7 & .441 & 6.301 & 100.000 & & & & & \\
\hline
\end{tabular}

Table 2 illustrates the total variance interpretation of the factor analysis. In the factor sampling analysis, the same values as the sample variables are input, and all the 16 common factors are extracted. It is given that the eigenvalue of each common factor, the percentage of the variance in the total variance and the cumulative percentage. Then three of the biggest factors whose eigenvalues are larger than 1 are chosen and set as public factors, and the cumulative percentage is $68.027 \%$. The non-rotation factor load matrix is obtained, and then the load matrix is transformed by the varimax rotation method. Finally, the orthogonal factor matrix after rotation is obtained (Table 3) 
Table 3. Indicators of physical quality test results

\begin{tabular}{|c|l|l|l|}
\hline \multirow{2}{*}{} & \multicolumn{3}{|c|}{ Component } \\
\cline { 2 - 4 } & 1 & 2 & 3 \\
\hline 50-meters race & -.07 & -.80 & -.18 \\
& 4 & 3 & 2 \\
\hline Standing long & -.30 & .77 & .10 \\
jump & 2 & 0 & 1 \\
\hline Pull-up & .64 & -.37 & .02 \\
& 0 & 6 & 6 \\
\hline Seat flexion & .30 & -.06 & .79 \\
& 7 & 6 & 2 \\
\hline 1000 or 800 meters & -.31 & .16 & .78 \\
race & 0 & 7 & 2 \\
\hline
\end{tabular}

According to the above analysis, three main factors of the special physical quality of college table tennis students can be obtained. Then the factors are clustered by their factor load. According to the result of clustering, the three main factors are named as: upper limb strength factor (F1), lower limb strength factor $(\mathrm{F} 2)$, waist strength factor $(\mathrm{F} 3)$, and endurance factor $(\mathrm{F} 4)$.

\section{Test Result Analysis}

\section{Upper Limb Strength Factor Analysis}

The first factor F1 mainly includes pull-up, reflecting the explosive force and rotation force of the college students in table tennis exercise, which has a very significant role in winning the game, and its contribution rate is $29.683 \%$. Upper limb strength which is powerful enough is able to create a variety of high-quality batting, and is the vital trump card in the game and can create good chances of scoring.

Table tennis is a sport in which the unilateral upper limb is used, characterized by repeated high-speed and explosive movements. Therefore, the systematic exercise can improve the level of table tennis greatly.

As the principle of sports biomechanics illustrates, in some activities that do not require overcoming of the great resistance to produce fast movement speed, according to the characteristics of the sport, the orders of joint activities should be cooperated in a variety of ways, and small magnitude movements play an important role in the joint activities. Table tennis batting technology is not a typical upper limb whipping action, because not all of the technologies are aimed to achieve the maximum batting speed of the racket. It should be noted that the strength of small joints is also of great significance. In the development of special strength in table tennis exercise, some small joints should not be ignored, and the development of strength should be balanced.

\section{Lower Limb Strength Factor Analysis}

The second main factor F2 includes the 50-meter race and the standing long jump, reflecting the mobility ability and the degree of physical stability of college students in table tennis, with a contribution rate of $16.775 \%$. The balance and rapid movement of the lower limbs play a vital role in high-quality batting. Only the rapid movement can assure the most reasonable batting posture in the shortest time, and stable standing can help to complete batting with enough strength. Zhuang Zhdong said that 70 percent of the game of table tennis relies on the legs, and 30 percent on the hand, so the strength of the lower limbs is greatly needed in the sport of table tennis for college students.

The main purpose of the lower limb strength training is to improve the starting speed and the movement speed of the lower limbs. Since the lower limbs are required to bear the movement of the whole body, the absolute strength of the lower limbs is proposed higher requirements. When the standing of a person is particularly stable, which is called by the coaches as "to stable the platform", 
batting of the ball is stable, and otherwise they are not. Students should pay attention to the utilization of their own weight to complete the core strength training, complete a variety of strength action exercises under the formation of a variety of non-balanced tilt, and even stand on the skateboard to do barbell and dumbbell exercise. Balance training is significant to table tennis, and the purpose of the so-called conversion of the gravity center is actually in search of balance: balance of left and right, before and after.

Long jump is a measurement indicator of lower limb strength, and shifting of the ball is the indicator to determine special mobility ability of table tennis players. By comparing the test results of the lower limb strength level and the results of the athletes' specific mobility, it can be concluded that the power of the lower limbs is closely related to the specific mobility. The better the results of long jumps of an athlete in standing jump and stride-sideways-to-and-fro are, the better the results of the movements to shift the ball. That is, the table tennis players with better lower limb strength have better mobility ability. So the systematic lower limb strength training can be more effective to help college students to improve the quality of table tennis batting.

\section{Analysis of Strength Factor of Waist and Abdomen}

Seat flexion tests extent of stretch and flexibility of the joints, muscles and ligaments at the trunk, waist and other parts of body. Study shows that the seat body flexion test results of the table tennis classes are obvious improved. Therefore, we primarily suppose that the training of table tennis could improve the flexibility and extent of stretch of the body significantly. Sit-up is an item to test the human body abdominal muscle strength. Study shows that sit-up results of college students in all the classes have a significant improvement, in which the most obvious is in the table tennis classes. Therefore, we primarily suppose that the improvement of college students' waist strength has obvious advantages to increase the strength of the table tennis forehand attacks.

\section{Endurance Quality Factor Analysis}

The third main factor, including 1000-meter race, is the reflection of the ability to obtain competition effect for college students in long-time table tennis competitions, thus named as endurance quality factor, whose contribution rate is $13.886 \%$. A large number of energy consumption is inclined to influence the students as to the movement technology and psychological state in competitions, so adequate physical strength is one of the essential factors to gain advantage. Speaking from professional athletes: According to the research of Zhang Yingqiu, Beijing Sports University, for an intense table tennis game, the density is $25 \%$, waves of the arm are 1000 times, the blood pressure is increased by $16 \mathrm{mmHg}$ for the average number of 192 times, weight loss is $0.5-0.8 \mathrm{~kg}$ in average, and grip strength changes are random. The load in the game of a day can be described as: if we take the best results for example, there are 3 times, 6 sets and 18 games in average in a day, not including the time to pick the ball, the actual time of the game in a day is 150-180min, and large game would last 10-14 days generally. It can be concluded that the physical loads of the table tennis players are not less notable than athletes of other items. With the gradually narrowing of the technical and tactical level gaps among the world's top table tennis players, the key moments for the outcome of the game often depend on the special stamina, speed endurance, strength and other physical fitness of the players, and physical training would occupy a more important position in the future in table tennis training. Research of Kings Trillinger proposes that athletic table tennis is an endurance load of less severe average, and as the load lasts longer, the greater is the proportion of reliance on fat metabolism for energy of athletes. Liu Xun's research shows that table tennis is a medium-intensity aerobic metabolic exercise, and the energy consumption of athletes of loop with quick attacking and counterattack during chop is greater than those of quick attacking with loop and quick attacking. According to the energy consumption in one game, a table tennis player needs to intake about $3200 \mathrm{kcal}$ from the diet during the day to meet the needs of the energy consumption.

Although the intensity of the training of college students and the intensity of the games are less than that of athletes, even a best-of-three micro game still requires at least twenty balls. Encountering a well-matched opponent, a set of games is likely to last an hour or even longer, 
which requires a lot for college students to maintain the tension state in the game, and it means that the endurance quality of college students needs to be fully trained to maintain adequate energy in the game.

From a large number of data we found that the actual conditions of table tennis special endurance of college students are not optimistic, and training in this aspect is not systematic enough. Therefore, the appropriate strengthening of college students in physical fitness and endurance training of arm muscles and leg muscles can help to a degree to improve the level of table tennis.

\section{Conclusion and Suggestions}

(1)The special physical quality of college table tennis students in our country is composed of three factors (upper limb strength factor, lower limb strength factor, endurance quality factor) and four test indicator items.

(2)Due to the characteristics of education in China which make students ignore sport activities in the face of the pressure from the college entrance examination, and then get suddenly relaxed after entering colleges, their extracurricular time becomes irregular, and the majority of their extracurricular life is occupied by the internet, thus inclined to cause the decline of physical quality. The characteristics of the physical condition composition factors of college students in table tennis optional course classes fully demonstrate that favorable physical fitness is the basis of learning of the sport of table tennis. This requires students to lay emphasis on the usual physical training, select corresponding and suitable training methods, and launch planned, targeted and systematic physical quality training. Only in this way can there be desirable training results, and can the athletes lay a favorable basis of physical quality, so that they can maintain the advantage that Chinese table tennis sport holds a lead in the world.

\section{Acknowledgment}

This research was financially supported by the Fundamental Research Funds for Central University (Grant NO.JB2017079).

\section{References}

[1] The national institute of sport teaching material committee, Sports measurement and evaluation [M], Beijing, People's sport publishing house, pp.200, 1996.

[2] J. Y. Liu and L. Sui, The statistical analysis of special characteristics of physical structure of China's elite short --distance speed skating women athletes, Journal of Tianjin University of Sport, vol.2, pp. 177-180, 2009.

[3] J. S. Qu and J. H. Huang, Event-related stamina training of Ping-pong, Journal of Wuhan Institute of Physical Education, vol.3, pp. 77-79, 2003.

[4] Y. Shao, The empirical research on the effects on various PE education subjects on the student corporeity from nonprofessional project [D], Beijing Sport University, 2013.

[5] W. D. Xu, Influence of different P.E. optional courses on college student physical quality, Liaoning Sport Science and Technology, vol.1, pp. 86-88, 2004.

[6] Abigail Strong, Mark Stoutenberg, and Anita Hobson-Powel, An evaluation of physical activity training in Australian medical school curricula, Journal of Science and Medicine in Sport, Available online 28 October 2016, ISSN 1440-2440. 